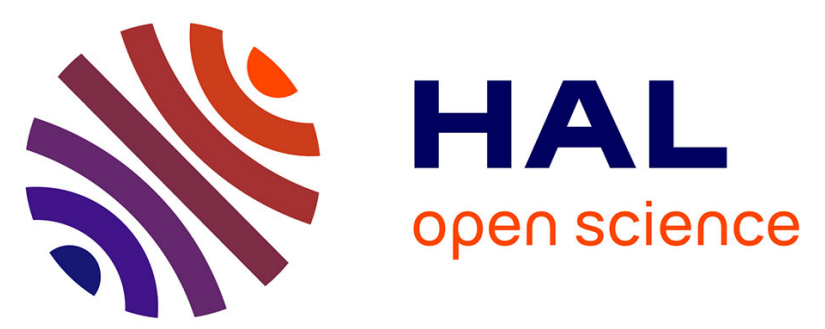

\title{
Organometallic-Mediated Alternating Radical Copolymerization of tert -Butyl-2-Trifluoromethacrylate with Vinyl Acetate and Synthesis of Block Copolymers Thereof
}

Sanjib Banerjee, Vincent Ladmiral, Antoine Debuigne, Christophe

Detrembleur, S. M. Wahidur Rahaman, Rinaldo Poli, Bruno Ameduri

\section{To cite this version:}

Sanjib Banerjee, Vincent Ladmiral, Antoine Debuigne, Christophe Detrembleur, S. M. Wahidur Rahaman, et al.. Organometallic-Mediated Alternating Radical Copolymerization of tert -Butyl-2Trifluoromethacrylate with Vinyl Acetate and Synthesis of Block Copolymers Thereof. Macromolecular Rapid Communications, 2017, 38 (15), pp.1700203-1700210. 10.1002/marc.201700203 . hal01836609

\section{HAL Id: hal-01836609 https://hal.science/hal-01836609}

Submitted on 1 Mar 2021

HAL is a multi-disciplinary open access archive for the deposit and dissemination of scientific research documents, whether they are published or not. The documents may come from teaching and research institutions in France or abroad, or from public or private research centers.
L'archive ouverte pluridisciplinaire HAL, est destinée au dépôt et à la diffusion de documents scientifiques de niveau recherche, publiés ou non, émanant des établissements d'enseignement et de recherche français ou étrangers, des laboratoires publics ou privés. 
DOI: 10.1002/marc.((insert number)) ((or ppap., mabi., macp., mame., mren., mats.))

\title{
Communication
}

\section{Organometallic-Mediated Alternating Radical Copolymerization of tert- Butyl-2-trifluoromethacrylate with Vinyl Acetate and Synthesis of Block Copolymers Thereof ${ }^{\mathrm{a}}$}

Sanjib Banerjee, ${ }^{[a]}$ Vincent Ladmiral, ${ }^{[a]}$ Antoine Debuigne, ${ }^{[b]}$ Christophe Detrembleur, ${ }^{[b]}$ S. M. Wahidur Rahaman, ${ }^{[\mathrm{c}]}$ Rinaldo Poli, ${ }^{[\mathrm{c}],[\mathrm{d}]}$ and Bruno Ameduri, ${ }^{*}[\mathrm{a}]$

\author{
${ }^{[\mathrm{a}]}$ Dr. S. Banerjee, Dr. V. Ladmiral, Dr. B. Ameduri \\ Ingénierie et Architectures Macromoléculaires, Institut Charles Gerhardt, UMR 5253 CNRS, \\ UM, ENSCM, Place Eugène Bataillon, 34095 Montpellier Cedex 5, France \\ E-mail: bruno.ameduri@enscm.fr \\ ${ }^{[b]}$ Dr. A. Debuigne, Dr.C. Detrembleur \\ Center for Education and Research on Macromolecules (CERM), University of Liege, \\ CESAM Research Unit, Sart-Tilman B6a, 4000 Liege, Belgium \\ ${ }^{[c]}$ Dr. S. M. Wahidur Rahalan, Prof. R. Poli \\ CNRS, LCC (Laboratoire de Chimie de Coordination) and Université de Toulouse, UPS, \\ INPT, 205 route de Narbonne, BP 44099, 31077 Toulouse Cedex 4, France \\ ${ }^{[\mathrm{d}]}$ Prof. R. Poli \\ Institut Universitaire de France, 1, rue Descartes, 75231 Paris Cedex 05, France
}

Organometallic-mediated radical polymerization (OMRP) has given access to well-defined poly(vinyl acetate-alt-tert-butyl-2-trifluoromethacrylate)- $b$-poly(vinyl acetate) and poly(VAcalt-MAF-TBE) copolymers composed of two electronically distinct monomers: vinyl acetate (VAc, donor, D) and tert-butyl-2-trifluoromethacrylate (MAF-TBE, acceptor, A), with low dispersity $(\leq 1.24)$ and molar masses up to $57,000 \mathrm{~g} / \mathrm{mol}$. These copolymers have a precise $1: 1$ alternating structure over a wide range of comonomer feed compositions. The reactivity ratios are determined as $r_{V A c}=0.01 \pm 0.01$ and $r_{M A F-T B E}=0$ at $40{ }^{\circ} \mathrm{C}$. Remarkably, from a feed containing $>50 \%$ molar VAc content, poly(VAc-alt-MAF-TBE)- $b$-PVAc block copolymers are produced via a one pot synthesis. Such diblock copolymers exhibit two glass transition temperatures attributed to the alternating and homopolymer sequences. The OMRP of this

\footnotetext{
a Supporting Information is available online from the Wiley Online Library or from the author.
} 
fluorine-containing alternating monomer system may provide access to a wide range of new polymer materials.

FIGURE FOR ToC_ABSTRACT

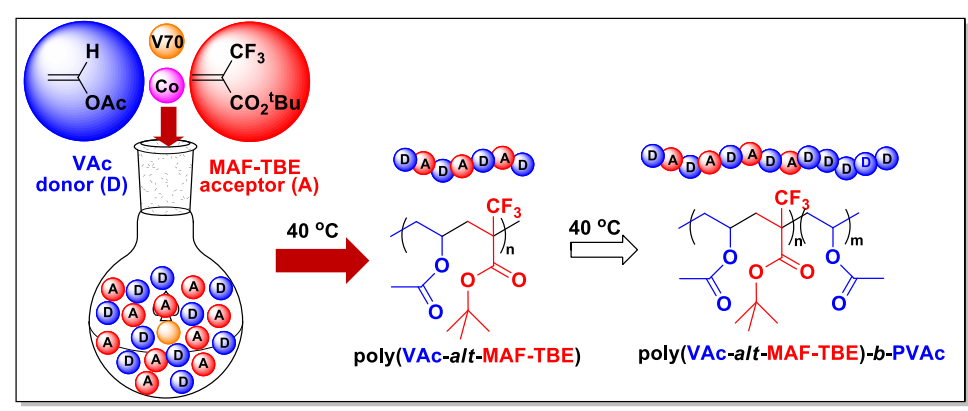




\section{Introduction}

Fluorinated homopolymers are unique materials with outstanding properties for high value added applications. The incorporation of sequences of these polymers into a di- or multiblock ${ }^{[1]}$ structure is expected to lead to materials of even greater value. To this end, the use of reversible deactivation radical polymerization (RDRP) synthetic techniques should be ideal in most cases. Indeed, Daikin was the first company to develop such materials over 35 years ago, ${ }^{[2]}$ leading to the industrial scale production of segmented thermoplastic elastomers. ${ }^{[3]}$ Since these pioneering works, interest in fluorinated block copolymers ${ }^{[4]}$ has surged in the last decade. This led to the synthesis of a variety of fluorinated block copolymers prepared using telomerization, ${ }^{[5-8]}$ conventional radical polymerization from functionalized initiators, ${ }^{[9-12]}$ click chemistry ${ }^{[13]}$ and using different RDRP techniques ${ }^{[4,}$ 14]. iodine transfer polymerization (ITP), ${ }^{[15-17]}$ photoinitiated $\mathrm{ITP},{ }^{[18]}$ reversible addition fragmentation chain transfer (RAFT) polymerization, ${ }^{[9,}$ 19-22] and atom transfer radical polymerization (ATRP.) ${ }^{[5,7,8]}$ However, for all their merits, telomerization only affords oligomers, and functional initiators lead to broad dispersity.

Alternating copolymers have been reported to constitute a valuable tool to build copolymers with some degree of sequence control. ${ }^{[23]}$ To date, only a few comonomer pairs have been reported to undergo alternating radical copolymerization such as styrene/maleic anhydride, ${ }^{[24]}$ styrene/maleimide derivatives, ${ }^{[25]}$ styrene/methacrylates (in the presence of Lewis acids), ${ }^{[26]}$ $N$-substituted maleimides/1-methylenebenzo-cycloalkanes, ${ }^{[27]}$ chlorotrifluoroethylene/vinyl ether ${ }^{[28]}$ and vinyl ethers/methacrylates. ${ }^{[29]}$ For other monomer pairs, highly ordered monomer sequence control is still challenging. ${ }^{[30]}$ Regarding fluorinated polymers, recently, Studer and coworkers $^{[31]}$ and the Scherf's team ${ }^{[32]}$ attempted the synthesis of predominantly alternating copolymers composed of hexafluoroisopropyl acrylate with 7-octenyl vinyl ether and $\mathrm{N}$ dialkylated benzothiadiazolodithienopyrrole with a dibrominated terephthalophenone derivative, respectively. Recently, Jordan's group reported (phosphinoarenesulfonate)Pd 
fluoride complex catalyst reactivation following $\beta$-F elimination in ethylene/vinyl fluoride copolymerization. ${ }^{[33]}$

2-(Trifluoromethyl)acrylic acid (MAF) and alkyl 2-trifluoromethacrylate (MAF-esters) are very interesting monomers. Although homopolymers can be produced anionically, ${ }^{[34]}$ these monomers do not homopolymerize under radical conditions, ${ }^{[35-37]}$ but can be copolymerized together with electron-donating monomers such as vinyl ethers. ${ }^{[35]}$ MAF- and MAF-esterscontaining fluorinated copolymers led to suitable materials for molecularly imprinted polymers, microlithography, polymer electrolyte membranes for fuel cells and for Li-ion batteries. ${ }^{[35]}$ Recently, a nitroxide-mediated alternating copolymerization of VAc and MAFTBE has been achieved. ${ }^{[38]}$ However, the polymerization control was not entirely satisfactory and attempts to synthesize block copolymers failed even with styrene, probably because the $\mathrm{C}-\mathrm{ON}$ bond at the chain-ends cannot be cleaved at a reasonably low temperature. ${ }^{[39]}$.

This contribution aims at developing a well-controlled radical copolymerization of VAc and MAF-TBE by organometallic mediated radical polymerization (OMRP) using cobalt(II) acetylacetonate, $\left[\mathrm{Co}(\mathrm{acac})_{2}\right]$ as a controlling agent. ${ }^{[40,41]}$ It is focused on this particular RDRP technique due to its ability to efficiently control the polymerization of several non-conjugated monomers, ${ }^{[42,43]}$ in particular VAc. ${ }^{[42,43]}$ Notably, RDRP of VAc was only achieved using a few techniques: reversible addition fragmentation chain transfer (RAFT) polymerization, ${ }^{[44]}$ iodine transfer polymerization (ITP) ${ }^{[45]}$ and organometallic-mediated radical polymerization (OMRP). ${ }^{[42]}$ Following a straightforward "one-pot" approach, a series of well-defined fluorinated copolymers was prepared including 1:1 alternating VAc-MAF-TBE copolymers as well as block copolymers where this poly(VAc-alt-MAF-TBE) alternating sequence is followed by a PVAc homopolymer block (Scheme 1). Although the "one-pot" strategy to prepare copolymer- $b$-polymer architectures was reported previously, ${ }^{[46-48]}$ its implementation in combination with OMRP to synthesize a novel block copolymer (containing a fluorinated alternating block) is unprecedented. 


\section{Results and Discussion}

The homopolymerization of VAc initiated by 2,2'-azobis (4-methoxy-2,4dimethylvaleronitrile) $(\mathrm{V}-70)$ in the presence of $\left[\mathrm{Co}(\mathrm{acac})_{2}\right]$ at $40{ }^{\circ} \mathrm{C}$ produced PVAc with controlled molar mass $\left(M_{n}=28,200 \mathrm{~g} / \mathrm{mol}\right)$ and low dispersity $(\bigoplus=1.16)$, as previously described $^{[49]}$ (entry 1 in Table $\mathrm{S} 1$ and Figure S1). In contrast, attempts to obtain a MAF-TBE homopolymer under the same conditions failed (entry 2, Table S1), as expected, since MAFTBE does not homopolymerize under radical conditions. ${ }^{[35-37]}$

The OMRP of VAc with MAF-TBE was initiated by $\mathrm{V}-70 / \mathrm{Co}(\mathrm{acac})_{2}$ in bulk at $40{ }^{\circ} \mathrm{C}$ (Scheme 1) using various MAF-TBE feed contents $\left(f_{M A F-T B E}\right)$ ranging from 0.1 to 0.9 ) (entries 3-8, Table S1). The reaction progress (conversions of VAc and MAF-TBE) was monitored by ${ }^{1} \mathrm{H}$ (equation $\mathrm{S} 1$ ) and ${ }^{19} \mathrm{~F}$ (equation S2) NMR spectroscopies. Figures S2-S3 show representative stack plots of two such ${ }^{1} \mathrm{H}$ NMR kinetic experiments using different VAc/MAF-TBE comonomer feed ratios, $f_{M A F-T B E}=0.5$ and 0.1 , respectively. Figure S4 exhibits a corresponding time evolution of the ${ }^{19} \mathrm{~F}$ NMR spectra for $f_{M A F-T B E}=0.5$. In all cases, equimolar conversions of VAc and MAF-TBE were recorded, until the depletion of MAFTBE (Figure 1 and Figures S5-S10), suggesting highly alternating copolymerizations (entries 3-8, Table S1). The ${ }^{1} \mathrm{H}$ NMR spectra (Figure S2) corresponding to the copolymerization with $f_{M A F-T B E}=0.5$, display a complex signal around $5.20 \mathrm{ppm}$, assigned to the $-\mathrm{CH}$ group of VAc in the VAc-MAF-TBE alternating dyads. This complex shape probably results from the adjacent stereocenters in VAc and MAF-TBE units. In contrast, copolymerizations using higher VAc feed contents $\left(f_{M A F-T B E}=0.1,0.2\right.$ and 0.3$)$ and continued beyond the complete MAF-TBE consumption, led to poly(VAc-alt-MAF-TBE)-b-PVAc block copolymers, as evidenced by the appearance of an additional NMR signal centered at $4.80 \mathrm{ppm}$ characteristic of the - $\mathrm{CH}$ group of VAc in the PVAc block ${ }^{[50]}$ (Figure S3). 
The semilogarithmic kinetic plots of these copolymerizations (carried out at $f_{M A F-T B E}=0.1$, 0.2 and 0.3, Figures S11-S13) displayed three distinct regimes: a short (30-45 min) induction period (such induction period was already observed for the CMRP of VAc), a relatively fast copolymerization reaction (until complete MAF-TBE consumption), and a slower homopolymerization of VAc, as confirmed by entry 1 , Table S1 $\left(f_{V A c}=1.0\right)$. Both segments of the plots are linear indicating that both the copolymerization and the homopolymerization followed first order kinetics. As expected, for copolymerizations using 1:1 VAc:MAF-TBE and an excess of MAF-TBE $\left(f_{M A F-T B E}=0.7\right.$ and 0.9$)$, the semilogarithmic plots (Figures S14S16) exhibited only one regime corresponding to the alternating copolymerization. When there is no more VAc in the comonomer feed, the polymerization stops. The apparent propagation rate constant of the copolymerization $\left(k_{p(a p p)}\right)$ was determined from the slope of the first order kinetic plots $\left(\ln \left([\mathrm{M}]_{0} /[\mathrm{M}]\right)\right.$ vs. $t$, Figure S17a).${ }^{[51]}$ The $k_{p(a p p)}$ vs. $f_{M A F-T B E}$ plot (Figure S17b) reveals a bell-shaped curve with a maximum at $f_{M A F-T B E}=0.5\left(k_{p(a p p)}=3.9 \times\right.$ $10^{-4} \mathrm{~s}^{-1}$ ) that is in further agreement with an alternating copolymerization. The SEC traces (Figure 2a and Figures S18a-S22a) remained monomodal throughout the polymerization and the $M_{n}$ vs. conversion plots (Figure 2b and Figures $\mathbf{S 1 8 b - S 2 2 b}$ ) show a regular increase of $M_{n}$ with monomer conversion, maintaining narrow $Ð$. These features are consistent with RDRP.

To gain further insight on the controlling mechanism, we have compared the bond dissociation free energy (BDFE) for the putative (acac) $)_{2} \mathrm{Co}-\mathrm{VAc}-\mathrm{coP}$ and (acac) ${ }_{2} \mathrm{Co}-\mathrm{MAF}-$ TBE-coP dormant species $($ coP $=$ copolymer) by DFT calculations, using model systems where the coP chain beyond the Co-bonded monomer was replaced by an $\mathrm{H}$ atom (details are in SI, Pages S7-S8 and Table S2). These new calculations integrated thermal and dispersion corrections, relative to those previously published for $(\mathrm{acac})_{2} \mathrm{Co}-\mathrm{VAc}-\mathrm{H}^{[52]}$ The resulting BDFE for the Co-VAc bond is $31.4 \mathrm{~kJ} / \mathrm{mol}$, whereas that of the Co-MAF-TBE is only 8.4 $\mathrm{kJ} / \mathrm{mol}$, suggesting a much higher lability of the latter. 
In order to study the nature of the chain ends, the controlled copolymerization of VAc/MAF-TBE $(80 / 20)$ was initiated from a PVAc $<4-\mathrm{Co}(\mathrm{acac})_{2}$ initiator and monitored by spin trapping electron paramagnetic resonance (EPR) experiments (Figures 3 and S23-S24). Along the polymerization, the dormant species were isolated from aliquots of the reaction mixture and reacted with the tert-butyl nitroso ('BuNO) spin trap. ESR-a and ESR-c spectra corresponding to $\mathrm{PVAc}<4-\left({ }^{\mathrm{B}} \mathrm{Bu}\right) \mathrm{NO} \bullet$ and to the final poly(VAc-alt- MAF-TBE)- $b-\mathrm{PVAc}-\mathrm{NO}{ }^{*}$, respectively, appear interpretable as the overlap of two different triplets of doublets $(d t)$, with similar hyperfine splittings for the doublets but slightly different ones for the triplets. Each of these $d t$ envelopes results from the coupling of the radical with $\mathrm{N}(1: 1: 1$ triplet) and $\mathrm{H}$ of CHOAc (doublet) and probably derives from a different stereochemistry ( $m$ and $r$ ) of the last dyad (components A and B). Simulation of ESR-a (Figure S23) using this model and isotropic parameters gave a satisfactory fit, with component $\mathrm{A}(64.5 \%)$ having $a_{\mathrm{N}}=36.1 \mathrm{MHz}$ and $a_{\mathrm{H}}=$ 4.38 MHz, and component B (45.5\%) having $a_{\mathrm{N}}=41.2 \mathrm{MHz}$ and $a_{\mathrm{H}}=3.81 \mathrm{MHz}$. In contrast, the intermediate $E S R$ - $b$ spectrum corresponding to the trapping of the intermediate poly(VAcalt-MAFTBE)-Co(acac) $)_{2}$ species that is present during the alternating copolymerization regime appears as a mixture of two signals: a major 1:1:1 triplet assigned to PMAF$\operatorname{TBE}\left({ }^{\mathrm{t}} \mathrm{Bu}\right) \mathrm{NO} \cdot$, in which only the coupling of the unpaired electron with the $\mathrm{N}$ nucleus is visible, and a smaller feature corresponding to PVAc-NO. Although no quantitative information can be deduced, this observation suggests that both types of chain ends (P-MAF$\mathrm{TBE}^{*}$ and $\mathrm{P}^{-\mathrm{VAc}}{ }^{\circ}$ ) might be reversibly trapped by $\mathrm{Co}(\mathrm{acac})_{2}$ in the alternating copolymerization regime.

Confirmation of the alternating structure was obtained by ${ }^{1} \mathrm{H},{ }^{19} \mathrm{~F},{ }^{13} \mathrm{C}$ and $2 \mathrm{D}$ NMR characterizations. The detailed NMR assignments are available in the supporting information (Figures S25-S32). MALDI-TOF spectrometry of both poly(VAc-alt-MAF-TBE) alternating copolymer and poly(VAc-alt-MAF-TBE)- $b$-PVAc block copolymer was also attempted to confirm and determine the monomer sequences but these analyses gave inconclusive results. 
Actually, NMR spectroscopy evidences and the determination of the reactivity ratios (see below) constitute sufficiently solid proofs to claim alternating microstructures of these polymers.

The OMRP kinetics enabled us to determine the reactivity ratios of these monomers (details are in SI, Page S7). The copolymer-monomer composition curve (Figure 4) reveals that the copolymer composition is always $1: 1$, independent of the feed composition. These data points, fitted with the Mayo-Lewis copolymerization equation ${ }^{[53]}$ (S3) provide the following reactivity ratios: $r_{V A c}=0.01 \pm 0.01$ and $r_{M A F-T B E}=0$ at $40^{\circ} \mathrm{C}$. These values are close to zero, which illustrates exclusive cross-propagation leading to alternating copolymerization, independent of the comonomer feed.

The thermal properties of these copolymers were studied by thermogravimetric analysis and differential scanning calorimetry (DSC). The $21 \%$ weight loss of the poly(VAc-alt-MAFTBE) copolymer just above $150{ }^{\circ} \mathrm{C}$ ( $v s$. a reduced weight loss for the block copolymer and no loss for PVAc, Figure S33) matches the value calculated for the loss of the carbo-tert-butoxy groups of the MAF-TBE monomers. It is likely due to the tert-butyl ester group decomposition into a carboxylic acid function with release of isobutene, followed by the decarboxylation of the carboxylic acid group (Scheme S1). ${ }^{[54]}$ The polymers exhibited glass transition temperatures $\left(T_{g}\right.$ 's) depending on both the monomer compositions and sequences (Figure 5). PVAc $\left(T_{g}=40{ }^{\circ} \mathrm{C}\right)$ and poly(VAc-alt-MAF-TBE) alternating copolymer $\left(T_{g}=\right.$ $\left.72{ }^{\circ} \mathrm{C}\right)$ displayed a single $T_{g}$. The poly(VAc-alt-MAF-TBE)-b-PVAc copolymer exhibited two $T_{g}$ 's at $43^{\circ} \mathrm{C}$ and $67^{\circ} \mathrm{C}$, which correspond to those of the PVAc homopolymer and of the poly(VAc-alt-MAF-TBE) alternating copolymer, respectively.

\section{Conclusions}

A simple approach for the preparation of well-defined 1:1 alternating VAc (electrondonating): MAF-TBE (electron-accepting) copolymers and a novel diblock copolymer 
(composed of one alternating block and one PVAc homopolymer sequence) by OMRP has been described. This is the first report on the synthesis of a fluorinated copolymer using OMRP. The relative length of the two blocks can be varied by simply tuning the comonomer feed ratio. The very low reactivity ratios account for the nearly perfect alternating copolymer structure over the whole tested range of comonomer feeds. Due to the remarkable properties of the fluorinated groups (low refractive index/dielectric constant, and interesting surface properties), the resulting copolymers are of interests for potential applications in high value added materials (e.g., coatings for optics, lithography, to prepare graft copolymer surfactants and fluorinated hydrophilic copolymer for membranes for water purification. This one-pot synthetic strategy will further contribute to the development of high-performance sequencespecific copolymers, a step toward advanced materials.

\section{Supporting Information}

Supporting Information is available from the Wiley Online Library or from the authors.

Acknowledgements: The authors thank Tosoh F-Tech Company (Shunan, Japan) and Akzo Nobel (Chalons sur Marne, France) for providing MAF-TBE and BTBCP, respectively. Financial support from the French National Agency (ANR grant FLUPOL) is greatly appreciated. C.D. and A.D. are Research Director and Research Associate by F.R.S.-FNRS, respectively, and thank FNRS for financial support. We also thank Lionel Rechignat for the simulation of the EPR spectrum. This work was granted access to the HPC resources of IDRIS under the allocation 2016-086343 made by GENCI (Grand Equipement National de Calcul Intensif) and to the resources of the CICT (Centre Interuniversitaire de Calcul de Toulouse, project CALMIP).

Received: Month XX, XXXX; Revised: Month XX, XXXX; Published online: 
((For PPP, use "Accepted: Month XX, XXXX" instead of "Published online")); DOI: 10.1002/marc.((insert number)) ((or ppap., mabi., macp., mame., mren., mats.))

Keywords: alternating copolymerization, block copolymer, organometallic mediated radical polymerization, fluoromonomer, one pot synthesis

[1] G. R. Riess, Prog. Polym. Sci. 2003, 28, 1107.

[2] M. Tatemoto, T. Nakagawa, US Patent 4,158,678 (assigned to Daikin) 19-06-1979

[3] F. Koji, Y. Yuji, M. Tatemoto, Eur. Pat. Appl. 1988. 0,272,698 (assigned to Daikin Kogyo Co. Ltd. Jap.).

[4] V. S. D. Voet, G. ten Brinke, K. Loos, J . Polym. Sci. Part A: Polym. Chem. 2014, 52, 2861.

[5] M. Destarac, K. Matyjaszewski, E. Silverman, B. Ameduri, B. Boutevin, Macromolecules 2000, 33, 4613.

[6] Z. Shi, S. Holdcroft, Macromolecules 2004, 37, 2084.

[7] Z. Shi, S. Holdcroft, Macromolecules 2005, 38, 4193.

[8] G. Laruelle, E. Nicol, B. Ameduri, J.-F. Tassin, N. Ajellal, J . Polym. Sci. Part A: Polym. Chem. 2011, 49, 3960.

[9] K. Xu, K. Li, P. Khanchaitit, Q. Wang, Chem. Mater. 2007, 19, 5937.

[10] C. Chanthad, K. A. Masser, K. Xu, J. Runt, Q. Wang, J. Mater. Chem. 2012, 22, 341.

[11] V. S. D. Voet, M. Tichelaar, S. Tanase, M. C. Mittelmeijer-Hazeleger, G. ten Brinke, K. Loos, Nanoscale 2013, 5, 184.

[12] V. S. D. Voet, D. Hermida-Merino, G. ten Brinke, K. Loos, $R S C A d v$. 2013, 3, 7938.

[13] R. Vukicevic, U. Schwadtke, S. Schmucker, P. Schafer, D. Kuckling, S. Beuermann, Polym. Chem. 2012, 3, 409.

[14] B. Ameduri, Macromolecules 2010, 43, 10163. 
[15] D. Valade, C. Boyer, B. Ameduri, B. Boutevin, Macromolecules 2006, 39, 8639.

[16] G. David, C. Boyer, J. Tonnar, B. Ameduri, P. Lacroix-Desmazes, B. Boutevin, Chem. Rev. 2006, 106, 3936.

[17] G. Lopez, A. Thenappan, B. Améduri, ACS Macro Lett. 2015, 4, 16.

[18] A. D. Asandei, Chem. Rev. 2016, 116, 2244.

[19] G. Kostov, F. Boschet, J. Buller, L. Badache, S. Brandsadter, B. Ameduri, Macromolecules 2011, 44, 1841.

[20] E. Girard, J.-D. Marty, B. Ameduri, M. Destarac, ACS Macro Lett. 2012, 1, 270.

[21] Y. Patil, B. Ameduri, Polym. Chem. 2013, 4, 2783.

[22] M. Guerre, S. M. Wahidur Rahaman, B. Ameduri, R. Poli, V. Ladmiral, Polym. Chem. 2016, 7, 6918 .

[23] J.-F. Lutz, M. Ouchi, D. R. Liu, M. Sawamoto, Science 2013, 341, 628

[24] E. G. L. Williams, B. Fairbanks, G. Moad, R. J. Mulder, E. Rizzardo, S. H. Thang, Polym. Chem. 2015, 6, 228.

[25] A. Oishi, H. Matsuoka, T. Yasuda, M. Watanabe, J. Mater. Chem. 2009, 19, 514.

[26] B. K. Denizli, J.-F. Lutz, L. Okrasa, T. Pakula, A. Guner, K. Matyjaszewski, J. Polym. Sci. Part A: Polym. Chem. 2005, 43, 3440.

[27] M. Hisano, K. Takeda, T. Takashima, Z. Jin, A. Shiibashi, A. Matsumoto, Macromolecules 2013, 46, 7733.

[28] F. Boschet, B. Ameduri, Chem. Rev. 2014, 114, 927.

[29] E. Mishima, S. Yamago, Macromol. Rapid Commun. 2011, 32, 893.

[30] K. Satoh, S. Ozawa, M. Mizutani, K. Nagai, M. Kamigaito, Nat. Commun. 2010, 1, 1.

[31] M. Tesch, J. A. M. Hepperle, H. Klaasen, M. Letzel, A. Studer, Angew. Chem. Int. Ed. 2015, 54, 5054.

[32] K.-J. Kass, M. Forster, U. Scherf, Angew. Chem. Int. Ed. 2016, 55, 7816.

[33] S. Wada, R. F. Jordan, Angew. Chem. Int. Ed. Engl. 2017, 56, $1820 .$. 
[34] T. Narita, Prog. Polym. Sci. 1999, 24, 1095.

[35] Y. Patil, B. Ameduri, Prog. Polym. Sci. 2013, 38, 703.

[36] H. Ito, B. Giese, R. Engelbrecht, Macromolecules 1984, 17, 2204.

[37] K. T. McElroy, S. T. Purrington, C. L. Bumgardner, J. P. Burgess, J. Fluorine Chem. 1999, 95, 117.

[38] S. Banerjee, I. Domenichelli, B. Ameduri, ACS Macro Lett. 2016, 1232.

[39] J.-F. Lutz, P. Lacroix-Desmazes, B. Boutevin, C. Le Mercier, D. Gigmes, D. Bertin, P. Tordo, Polym. Prepr. (Am. Chem. Soc., Div. Polym. Chem.) 2002, 43, 287.

[40] A. Debuigne, R. Poli, C. Jerome, R. Jerome, C. Detrembleur, Prog. Polym. Sci. 2009, 34,211

[41] A. Debuigne, C. Jerome, C. Detrembleur, Polymer 2017, DOI: 10.1016/j.polymer.2017.01.008.

[42] M. Hurtgen, C. Detrembleur, C. Jerome, A. Debuigne, Polym. Rev. 2011, 51, 188.

[43] R. Poli, Chem. Eur. J. 2015, 21, 6988.

[44] S. Harrisson, X. Liu, J.-N. Ollagnier, O. Coutelier, J.-D. Marty, M. Destarac, Polymers 2014, 6, 1437.

[45] M. C. Iovu, K. Matyjaszewski, Macromolecules 2003, 36, 9346.

[46] B. Lessard, M. Marić, Macromolecules 2010, 43, 879.

[47] D. Benoit, C. J. Hawker, E. E. Huang, Z. Lin, T. P. Russell, Macromolecules 2000, 33, 1505.

[48] M. Hurtgen, A. Debuigne, C.-A. Fustin, C. Jerome, C. Detrembleur, Macromolecules 2011, 44, 4623.

[49] A. Debuigne, J.-R. Caille, R. Jerome, Angew Chem Int Ed Engl 2005, 44, 1101.

[50] A. Debuigne, Y. Champouret, R. Jerome, R. Poli, C. Detrembleur, Chem. Eur. J. 2008, 14, 4046. 
[51] P. De, L. Sipos, R. Faust, M. Moreau, B. Charleux, J.-P. Vairon, Macromolecules $\mathbf{2 0 0 5}, 38,41$.

[52] A. N. Morin, C. Detrembleur, C. Jerome, P. De Tullio, R. Poli, A. Debuigne, Macromolecules 2013, 46, 4303.

[53] F. R. Mayo, F. M. Lewis, J. Am. Chem. Soc. 1944, 66, 1594.

[54] M. N. Wadekar, Y. R. Patil, B. Ameduri, Macromolecules 2014, 47, 13. 


\section{Scheme \& Figure Captions}

Scheme 1. Synthesis of either poly(VAc-alt-MAF-TBE) alternating copolymers or poly(VAcalt-MAF-TBE)- $b$-PVAc block copolymers by "one-pot” OMRP.

Figure 1: No. of mmol monomer conversion vs. time plot of VAc and MAF-TBE during the OMRP of VAc and MAF-TBE $\left(f_{M A F-T B E}=0.1\right)$ mediated by $\mathrm{V}-70 / \mathrm{Co}(\mathrm{acac})_{2}$ at $40{ }^{\circ} \mathrm{C}$ in bulk (entry 3, Table S1).

Figure 2: a) Evolutions of the SEC traces vs. time and b) plot of $M_{n}$ and $D$ vs. the total monomer conversion for the OMRP of VAc and MAF-TBE $\left(f_{M A F-T B E}=0.5\right)$ mediated by V$70 / \mathrm{Co}(\mathrm{acac})_{2}$ at $40{ }^{\circ} \mathrm{C}$ in bulk (entry 6, Table $\mathrm{S} 1$ ).

Figure 3: EPR spectra of the spin trapped PVAc-Co(acac) $)_{2}$, poly(VAc-alt-MAFTBE)$\mathrm{Co}(\mathrm{acac})_{2}$ and poly(VAc-alt-MAFTBE)- $b$-PVAc-Co(acac) $)_{2}$ (see Experimental Section in the SI for the detailed experimental conditions).

Figure 4: Evolution of copolymer-monomer composition curve for the OMRP of VAc with MAF-TBE mediated by $\mathrm{V}-70 / \mathrm{Co}(\text { acac })_{2}$ in bulk at $40{ }^{\circ} \mathrm{C}$.

Figure 5: DSC thermograms of pure PVAc, poly(VAc-alt-MAF-TBE) and poly(VAc-altMAF-TBE)- $b$-PVAc copolymers (entries 1, 6 and 3, respectively, Table S1). 


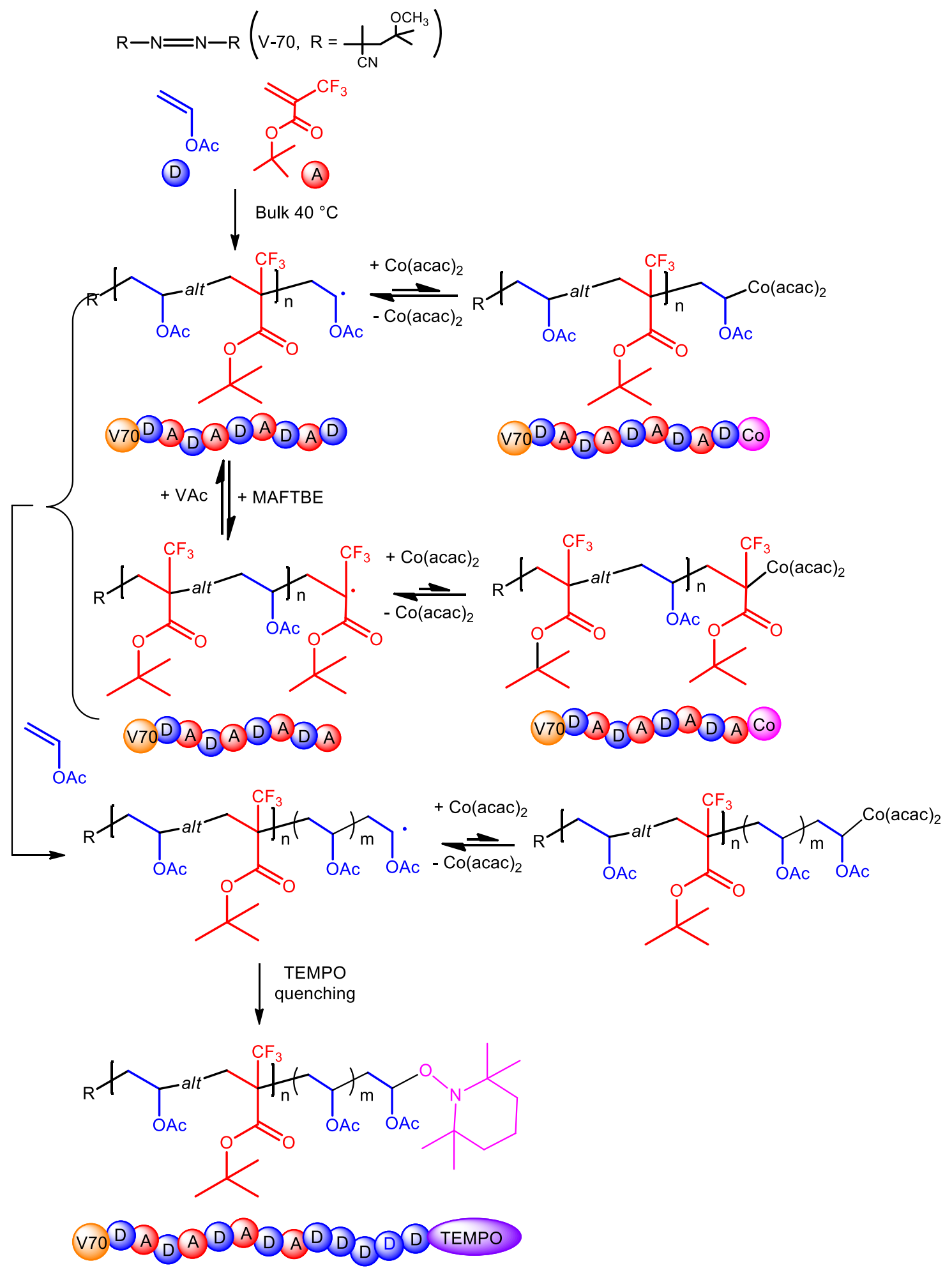

Scheme 1. Synthesis of either poly(VAc-alt-MAF-TBE) alternating copolymers or poly(VAcalt-MAF-TBE)- $b$-PVAc block copolymers by “one-pot” OMRP. 


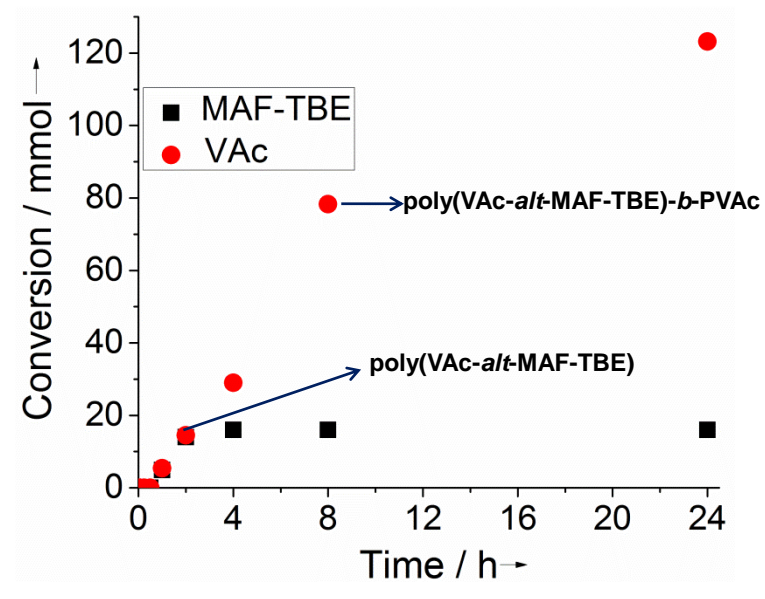

Figure 1. No. of mmol monomer conversion vs. time plot of VAc and MAF-TBE during the OMRP of VAc and MAF-TBE $\left(f_{M A F-T B E}=0.1\right)$ mediated by $\mathrm{V}-70 / \mathrm{Co}(\mathrm{acac})_{2}$ at $40{ }^{\circ} \mathrm{C}$ in bulk (entry 3, Table S1). 

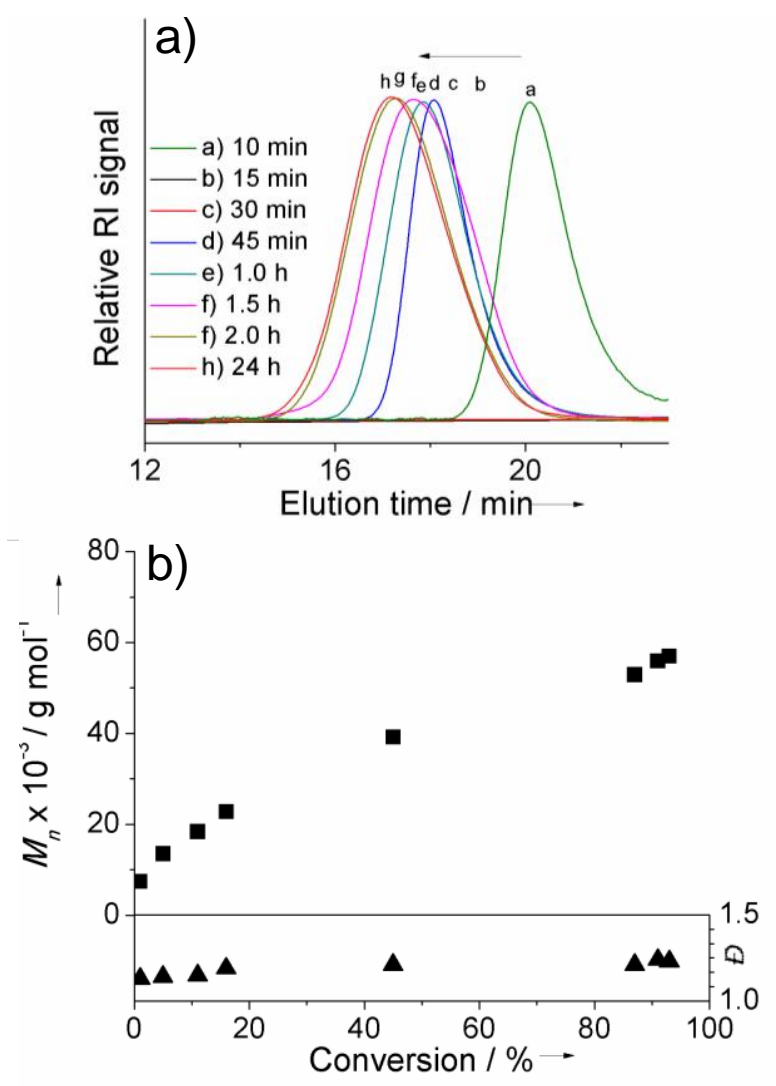

Figure 2. a) Evolutions of the SEC traces vs. time and b) plot of $M_{n}$ and $Ð v s$. the total monomer conversion for the OMRP of VAc and MAF-TBE $\left(f_{M A F-T B E}=0.5\right)$ mediated by V$70 / \mathrm{Co}(\mathrm{acac})_{2}$ at $40{ }^{\circ} \mathrm{C}$ in bulk (entry 6, Table $\mathrm{S} 1$ ). 


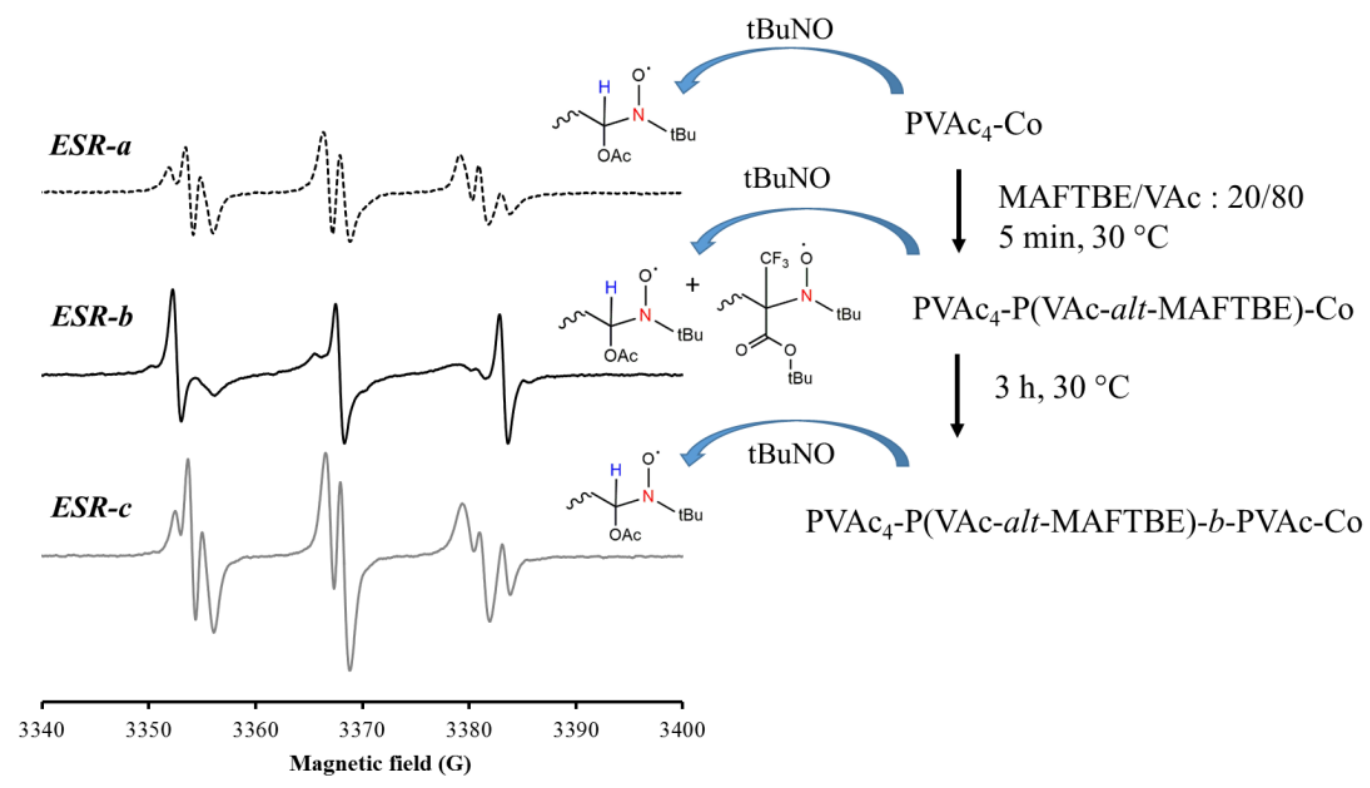

Figure 3. EPR spectra of the spin trapped PVAc-Co(acac)2, poly(VAc-alt-MAFTBE)$\mathrm{Co}(\mathrm{acac})_{2}$ and poly(VAc-alt-MAFTBE)- $b$-PVAc-Co(acac) $)_{2}$ (see Experimental Section in the SI for the detailed experimental conditions as well as simulated spectra). 


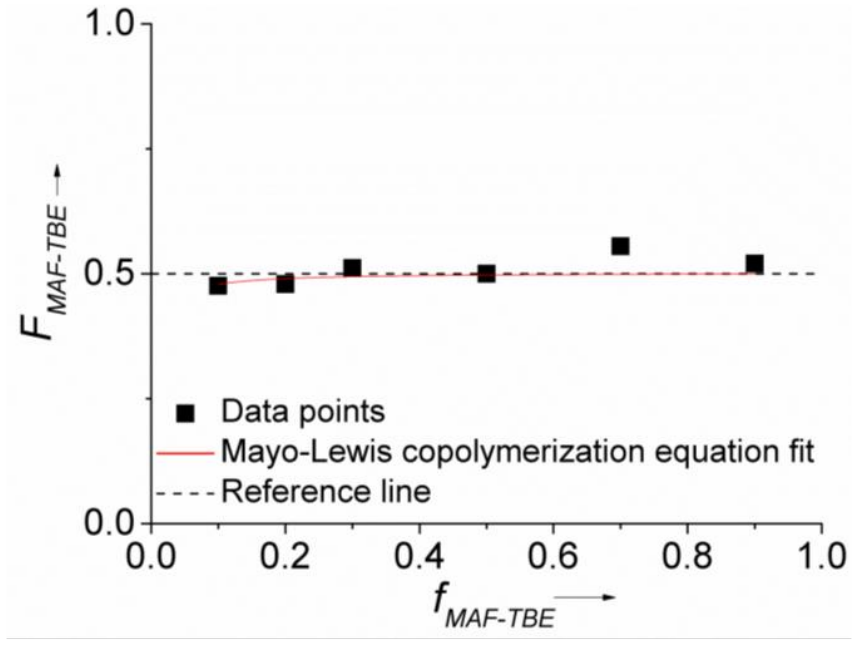

Figure 4. Evolution of copolymer-monomer composition curve for the OMRP of VAc with MAF-TBE mediated by $\mathrm{V}-70 / \mathrm{Co}(\text { acac })_{2}$ in bulk at $40{ }^{\circ} \mathrm{C}$. 


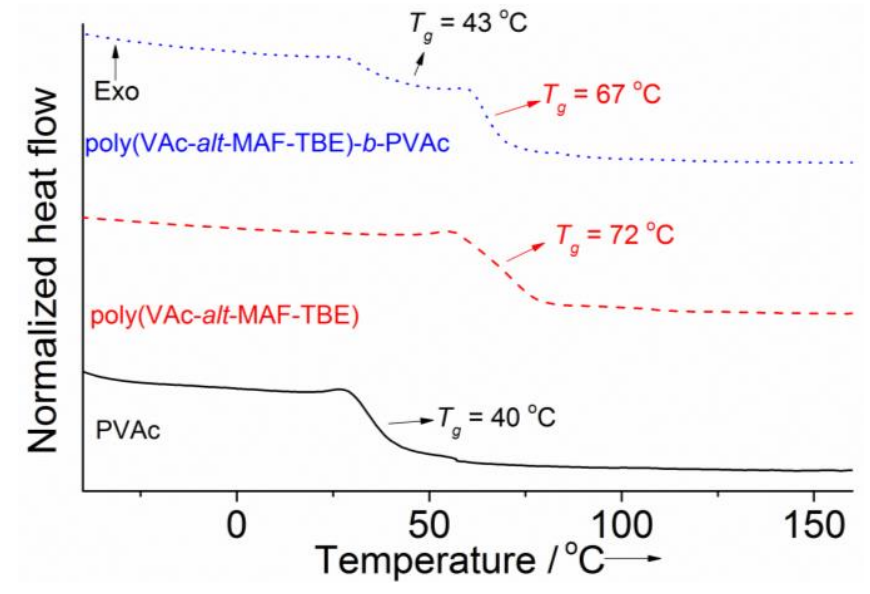

Figure 5. DSC thermograms of pure PVAc (black thermogram), poly(VAc-alt-MAF-TBE) (red dotted curve) and poly(VAc-alt-MAF-TBE)- $b$-PVAc copolymers (blue dotted curve) (entries 1, 6 and 3, respectively, Table S1). 
Organometallic-mediated radical copolymerization has been successfully employed for 1:1 alternating controlled copolymerization (independent of the monomer feed) of VAc (electron-donating) and MAF-TBE (electron-accepting). By simply tuning the comonomer feed ratio, well-defined poly(VAc-alt-MAF-TBE) alternating copolymers or novel poly(VAc$a l t$-MAF-TBE)- $b$-PVAc diblock copolymers (comprising of one alternating block and one homopolymer block) can be prepared.

Sanjib Banerjee, Vincent Ladmiral, Antoine Debuigne, Christophe Detrembleur, S. M. Wahidur Rahaman, Rinaldo Poli, and Bruno Ameduri*

Organometallic-Mediated Alternating Radical Copolymerization of tert-Butyl-2trifluoromethacrylate with Vinyl Acetate and Synthesis of Block Copolymers Thereof

ToC figure

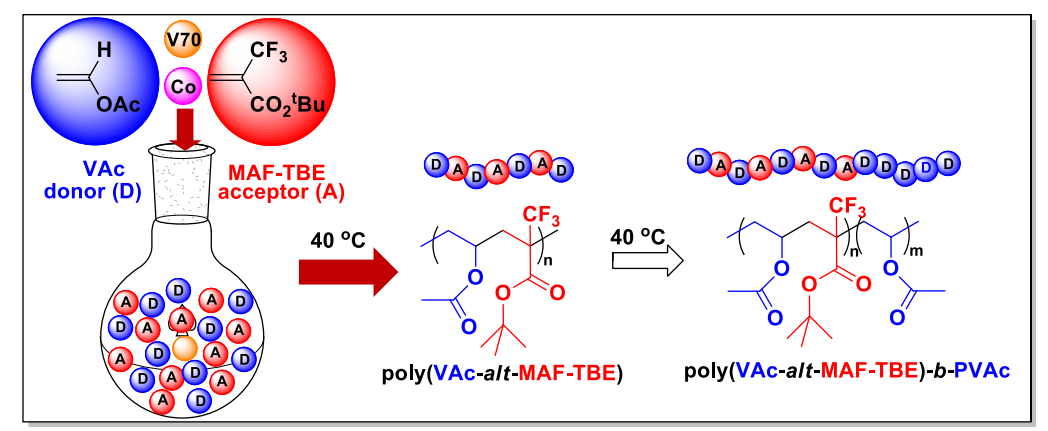

